\title{
Hepatitis $B$ vaccination uptake in hard-to-reach populations in London: a cross-sectional study
}

Josephine E. B. Taylor ${ }^{1}$, Julian Surey ${ }^{1}$, Jennifer MacLellan ${ }^{1}$, Marie Francis ${ }^{1}$, Ibrahim Abubakar ${ }^{1 *}$ and Helen R. Stagg ${ }^{1,2}$ (D)

\begin{abstract}
Background: In the UK, hepatitis B virus (HBV) incidence is associated with migrants from particular high-burden countries and population groups deemed 'hard-to-reach' by standard healthcare services: the homeless, people who inject drugs and ex-prisoners. Currently, there is a national targeted HBV vaccine policy for such at-risk groups, but there is limited recent evidence about 1) the levels of vaccine uptake, 2) the factors associated with incomplete vaccination, and 3) reasons for incomplete vaccination.
\end{abstract}

Methods: A questionnaire capturing social and medical history, demographic factors and information about HBV vaccination status was completed by individuals deemed hard-to-reach due to socio-structural factors that criminalise, isolate and stigmatise who consented to participate in a randomised controlled trial of a peer intervention to promote engagement with hepatitis $C$ services. The questionnaire also captured the reasons for incomplete vaccination. Descriptive, univariable and multivariable regression analyses were undertaken.

Results: Three hundred fourty six participants completed the questionnaire. 1) 52.3\% ( $n=181)$ reported full HBV vaccination. 2) Within a multivariable model adjusting for sociodemographic variables, the presence of one or two or more socio-structural factors that are included in the national targeted vaccination policy was associated with protection against incomplete HBV vaccination (51.7\% vaccine coverage in those with one factor, odds ratio 0.43 [95\% confidence interval 0.20-0.92]); 70.1\% coverage with two or more factors, 0.19 [0.09-0.39]; overall $p$-value $<0.001$ ). Being female was also associated with lower vaccine uptake (2.37 [1.24-4.57], 0.01). Examining the socio-structural factors individually, intravenous drug use was associated with protection against incomplete HBV vaccination. 3) The most common reasons declared for incomplete vaccination were never being offered the vaccine or not returning for further doses.

Conclusion: Within this study of HBV vaccination uptake among hard-to-reach population groups in London, UK, we document 52.3\% coverage of the full vaccine course. Critically, although participants recommended for immunisation within national guidelines had an increased likelihood of receiving a complete vaccine course, we note surprisingly low coverage in the presence of the risk factors that are national indicators for vaccination. Public health bodies should make additional efforts to improve coverage in the hard-to-reach through improved vaccine delivery systems.

Trial registration: ISRCTN24707359, Registered 19th October 2012.

Keywords: Hepatitis B virus, Vaccination, Hard-to-reach, Prisoners, Homeless, Injecting drug users

\footnotetext{
* Correspondence: i.abubakar@ucl.ac.uk

${ }^{1}$ Institute for Global Health, University College London, 4th floor, Mortimer

Market Centre, off Capper Street, London WC1E 6JB, UK

Full list of author information is available at the end of the article
}

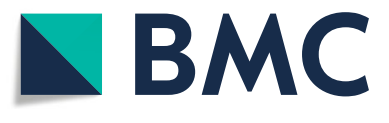

(c) The Author(s). 2019 Open Access This article is distributed under the terms of the Creative Commons Attribution 4.0 International License (http://creativecommons.org/licenses/by/4.0/), which permits unrestricted use, distribution, and reproduction in any medium, provided you give appropriate credit to the original author(s) and the source, provide a link to the Creative Commons license, and indicate if changes were made. The Creative Commons Public Domain Dedication waiver (http://creativecommons.org/publicdomain/zero/1.0/) applies to the data made available in this article, unless otherwise stated. 


\section{Background}

The global burden of hepatitis B virus (HBV) is substantial, with 257 million people living with chronic infection globally [1]. Chronic infections can lead to cirrhosis and hepatocellular carcinoma and cause around 500,000700,000 deaths a year [2]. In the UK in 2017, the incidence of infection was low at $0.80 / 100,000$, [3] but it was concentrated in specific population groups, including migrants from high burden countries and individuals deemed 'hard-to-reach' by healthcare services due to socio-structural factors that criminalise, isolate and stigmatise, such as homelessness, injecting drug use (IDU) and imprisonment $[4,5]$. In order to fulfil its commitment to viral hepatitis elimination by 2030 , the UK needs to effectively address infection prevention and treatment in these groups [6].

A HBV subunit vaccine has been available since 1982 and is $95 \%$ effective at preventing infection in people who have completed the three dose schedule (zero, one and six months) [7]. A rapid schedule can also be used (zero, seven and 21 days), with a fourth dose recommended for ongoing protection [8]. In the UK, HBV vaccination has historically been targeted towards population groups such as people who inject drugs (PWIDs), individuals who change sexual partners frequently (particularly men who have sex with men), patients with chronic liver disease (particularly with chronic hepatitis $\mathrm{C}$ virus infection $[\mathrm{HCV}]$ ), prisoners and those at occupational risk. These target groups are laid out in the Green Book, published by Public Health England (PHE) [8]. Since the autumn of 2017, HBV vaccination for all children aged one to 10 has also been incorporated into the UK immunisation schedule [8].

Although homelessness is not a specific indicator for HBV vaccination in the UK, this population group overlaps with the target groups of the Green Book. Previous research has highlighted the association between homelessness and tri-morbidity (the combination of physical and mental ill-health and substance abuse), unprotected sex, exposure to blood-borne viruses and IDU [9-14]. The cycle of homelessness and imprisonment is also well documented [15-17]. The homeless are disproportionately represented in the population of those experiencing the criminal justice system and homelessness can be a major factor in both offending and re-offending. There is often a lack of housing and support options available to individuals leaving custody. It has also been suggested that the homeless will re-offend to keep a roof over their head.

The latest figures estimate the homeless population in London to be over 164,000, with around 3\% living in single bed homeless hostels [18]. The majority of the rough-sleeping population in London identify as White British and White Other (35 and 28\%, respectively) [19]. The nationalities of the $46 \%$ of non UK-born rough sleepers is diverse. In recent years, the proportion of rough sleepers from Central and Eastern European Countries has declined (23\% in 2017/18 compared to $37 \%$ in $2015 / 16$ ). People born in Romania and Poland make up the two largest non-UK nationalities (9 and 8\% respectively) [19].

Individuals within these population groups often have difficulties in accessing traditional healthcare systems [5, 20]. Outreach services such as 'Find and Treat' in Londonwhich seeks to detect tuberculosis in hard-to-reach groups and support people through diagnosis and treatmentexist to meet the health needs of vulnerable individuals by engagement with homeless shelters, etc., but there is often a lack of coordination between boroughs and the National Health Service (NHS) [21].

In order to understand how effectively the national public health vaccination policy documented in the Green Book is being implemented among risk groups, this study aimed to assess the levels of HBV vaccine coverage in a hard-to-reach population in London, the epidemiological factors associated with coverage, and the individual reasons for not completing the vaccine course.

\section{Methods \\ Study design and participants}

The HALT: Hepatitis trial was a randomised non-blinded controlled trial to assess the efficacy of a Peer Advocacy intervention to promote engagement with healthcare services in individuals chronically infected with viral hepatitis [22]. Potential trial participants were approached through outreach services such as drug treatment centres, homeless hostels and day centres across London, UK between August 2013 and June 2015. The eligibility criteria were being hard-to-reach by normal healthcare services (evidenced by engagement with outreach services as a client), over the age of 16 years, and providing written informed consent. Individuals were excluded if they were already on treatment for hepatitis $\mathrm{C}$ virus (HCV) or HBV. In order to fully enrol in the trial, consenting participants had to test positive HBV or HCV infection.

This study is a cross-sectional analysis of the data collected at baseline from the potential trial participant population i.e. it does not exclude anyone by HBV or $\mathrm{HCV}$ status. A questionnaire captured self-reported demographic and clinical information, including whether participants had been vaccinated against $\mathrm{HBV}$ and how many doses they had received (Additional file 1). Participants were also asked to select a reason for not receiving the vaccine or receiving less than three doses.

\section{Study outcome}

The outcome of interest was having an incomplete self-declared HBV vaccination history (less than three doses). Self-declared HBV vaccination status was classified as: no doses, one dose, two doses, three or more doses, or unknown status. For the regression model, zero 
to two doses were combined into a single stratum (incomplete vaccination status).

\section{Exposures of interest}

Homelessness was collated into a variable with four strata: unknown, never homeless, ever homeless, or currently homeless. Current homelessness outranked previous homelessness. Drug use was categorised as current IDU, history of IDU, non-IDU (this captured those who stated that they had used drugs non-intravenously in the past or currently), no drug use, and unknown. Current IDU outranked history of IDU, IDU outranked non-IDU. Imprisonment was categorised into ever imprisoned, ever arrested but not imprisoned, neither, and unknown. Excessive alcohol consumption and smoking history was documented as present, absent, and unknown. Information about smoking combined into the single variable 'smoking history', which combined questions on the number of cigarettes a day and current or previous smoking to yield the strata Present, Absent, and Unknown.

Given the critical nature of the Green Book in providing vaccination guidance [8], the presence of zero, one, or two or more Green Book risk factors that should trigger the offer of vaccination were recorded in a single variable. The factors included were thus socio-structural factors that criminalise and stigmatise i.e. drug use, homelessness, imprisonment, being arrested, and liver disease (all from the baseline questionnaire), as well as $\mathrm{HCV}$ status derived from laboratory tests.

\section{Analysis}

Descriptive analyses were undertaken of vaccine uptake, the number of doses taken and reasons for not accepting a full course of vaccination.

Logistic regression models were used to identify factors associated with the outcome of complete HBV vaccination using Stata version 14. Initially, univariable models were built that included the Green Book classification of target groups (by socio-structural factors). As our analysis looked at multiple potential factors associated with vaccination status, all exposures from the univariable analyses were included in the multivariable model, which was assessed for model stability and collinearity. For consistency, the univariable models were restricted to the same participants as were included in the multivariable regression. Likelihood Ratio tests (LRTs) were used to examine a priori defined potential effect modification between Green Book risk factors and homelessness, Green Book risk factors and alcohol abuse, homelessness and alcohol abuse, and ethnicity and birthplace, as well as to assess if model fit was improved by the inclusion of age as a linear or categorical variable. Later analyses looked at the individual associations between the factors documented in the Green Book and vaccine uptake.

\section{Ethics}

This secondary data analysis was approved as part of the HALT: Hepatitis trial by the National Research Ethics Service (NRES) Committee London, Brent (ref: 13/LO/0077) and was registered as ISRCTN24707359 [23].

\section{Results}

\section{Participant characteristics}

Three hundred sixty four individuals consented for testing as part of the trial; of these 18 declared a previous HBV diagnosis and were thus excluded, leaving 346 (95.1\%). Table 1 describes the baseline characteristics of the remaining 346 participants. The majority were male (264/346, 76.3\%) and UK-born (263/346, 76.0\%), with a median age of 43 years (range 19-69). 176/346 (50.9\%) reported current or previous IDU, 289/346 current or previous homelessness (83.5\%) and 221/346 (63.9\%) imprisonment. 228/346 (65.9\%) participants reported receiving a previous HBV test. 157 (45.4\%) participants had two or more of the risk factors listed in the Green Book, with 246 (71.1\%) reporting at least one.

\section{Level of HBV vaccination}

The level of complete self-declared HBV vaccination in this cohort was $52.3 \%$ (Table 1). 227/346 (65.6\%) participants stated that they had received at least one dose of HBV vaccine. Of these, 181/227 (79.7\%) had a complete vaccination status (three doses), 15/227 (6.6\%) reported receiving one dose of $\mathrm{HBV}$ vaccine and 26/227 (11.5\%) reported receiving two doses. Participants reporting incomplete vaccination status (less than three doses) were more likely to be female $(52 \%, 43 / 82)$, have never been homeless $(51 \%, 26 / 51)$, to declare no drug use $(65 \%, 44 /$ 68 ), and to have never been imprisoned or arrested $(62 \%, 28 / 45)$. Examining the individuals with an unknown vaccination status revealed that they may be older, with a differing history of drug use, and imprisonment/arrest (Additional file 2).

When contributing risk factors were summarised into a single 'Green Book' variable, the percentage of participants with an incomplete vaccine status decreased from $58.4 \%$ (zero Green Book risk factors) to $40.5 \%$ (one) and $22.9 \%$ (two or more). When broken down into doses, the percentage of participants reporting zero and one dose of HBV vaccination was highest in those reporting zero Green Book risk factors (42.2 and 40.0\% respectively). In comparison, with two and three or more doses, the percentage was highest in participants with two or more Green Book risk factors (50.0 and 60.8\% respectively). 
Table 1 Baseline characteristics of the 346 participants, by number of doses of HBV vaccine

\begin{tabular}{|c|c|c|c|c|c|c|c|c|}
\hline \multirow[t]{2}{*}{ Variables } & \multicolumn{2}{|c|}{ Overall } & \multicolumn{2}{|c|}{ Incomplete vaccination status } & \multicolumn{2}{|c|}{ Complete vaccination status } & \multicolumn{2}{|c|}{ Unknown vaccination status } \\
\hline & $\#$ & $\mathrm{Col} \%$ & $\#$ & Row \% & $\#$ & Row \% & $\#$ & Row \% \\
\hline Overall & 346 & 100 & 130 & 37.6 & 181 & 52.3 & 35 & 10.1 \\
\hline \multicolumn{9}{|l|}{ Gender } \\
\hline Female & 82 & 23.7 & 43 & 52.4 & 30 & 36.6 & 9 & 11.0 \\
\hline Male & 264 & 76.3 & 87 & 33.0 & 151 & 57.2 & 26 & 9.8 \\
\hline Unknown & 0 & 0.0 & 0 & - & 0 & - & 0 & - \\
\hline \multicolumn{9}{|l|}{ Age } \\
\hline $19-29$ & 53 & 15.3 & 24 & 45.3 & 25 & 47.2 & 4 & 7.6 \\
\hline $30-39$ & 86 & 23.9 & 28 & 32.6 & 51 & 59.3 & 7 & 8.1 \\
\hline $40-49$ & 140 & 41.5 & 48 & 34.3 & 81 & 57.8 & 11 & 7.9 \\
\hline $50-59$ & 60 & 17.9 & 25 & 41.7 & 22 & 36.7 & 13 & 21.7 \\
\hline $60-69$ & 7 & 2.2 & 5 & 71.4 & 2 & 28.6 & 0 & 0.0 \\
\hline Unknown & 0 & 0.0 & 0 & - & 0 & - & 0 & - \\
\hline \multicolumn{9}{|l|}{ Ethnicity } \\
\hline White C/E European & 82 & 23.7 & 33 & 40.2 & 37 & 45.1 & 12 & 14.6 \\
\hline White Other & 160 & 46.8 & 53 & 33.1 & 89 & 55.6 & 18 & 11.3 \\
\hline Black African & 25 & 7.2 & 16 & 64.0 & 9 & 36.0 & 0 & 0.0 \\
\hline Black Other & 45 & 13.0 & 16 & 35.6 & 27 & 60.0 & 2 & 4.4 \\
\hline Mixed/Other & 32 & 9.2 & 11 & 34.4 & 18 & 56.3 & 3 & 9.4 \\
\hline Unknown & 2 & 0.6 & 1 & 50.0 & 1 & 50.0 & 0 & 0.0 \\
\hline \multicolumn{9}{|l|}{ Birthplace } \\
\hline Not UK born & 83 & 24.0 & 38 & 45.8 & 33 & 39.8 & 12 & 14.6 \\
\hline UK born & 263 & 76.0 & 92 & 35.0 & 148 & 56.2 & 23 & 8.7 \\
\hline Unknown & 0 & 0.0 & 0 & - & 0 & - & 0 & - \\
\hline \multicolumn{9}{|l|}{ Drug use } \\
\hline No drug use & 68 & 19.7 & 44 & 64.7 & 14 & 20.6 & 10 & 14.7 \\
\hline Non-IDU (History or current) & 101 & 29.2 & 43 & 42.6 & 44 & 43.6 & 14 & 13.9 \\
\hline History of IDU & 98 & 28.3 & 22 & 22.5 & 67 & 68.4 & 9 & 9.18 \\
\hline Current IDU & 78 & 22.5 & 20 & 25.6 & 56 & 71.8 & 2 & 2.6 \\
\hline Unknown & 1 & 0.0 & 1 & 100.0 & 0 & - & 0 & - \\
\hline \multicolumn{9}{|l|}{ Homelessness } \\
\hline Never & 51 & 14.7 & 26 & 51.0 & 21 & 41.2 & 4 & 7.8 \\
\hline History & 104 & 30.1 & 29 & 27.9 & 63 & 60.6 & 12 & 11.5 \\
\hline Current & 185 & 53.5 & 72 & 38.9 & 94 & 50.8 & 19 & 10.3 \\
\hline Unknown & 6 & 1.2 & 3 & 50.0 & 3 & 50.0 & 0 & - \\
\hline \multicolumn{9}{|l|}{ Imprisonment/Arrested } \\
\hline Neither & 45 & 13.0 & 28 & 62.2 & 12 & 26.7 & 5 & 11.1 \\
\hline Arrested but not imprisoned & 78 & 22.5 & 40 & 51.3 & 22 & 28.2 & 16 & 20.5 \\
\hline Imprisoned & 221 & 64.2 & 61 & 27.6 & 146 & 66.1 & 14 & 6.3 \\
\hline Unknown & 2 & 0.6 & 1 & 50.0 & 1 & 50.0 & 0 & - \\
\hline \multicolumn{9}{|l|}{ Excess alcohol consumption } \\
\hline No & 203 & 58.7 & 80 & 39.1 & 104 & 51.2 & 19 & 9.4 \\
\hline Yes & 141 & 40.8 & 50 & 35.5 & 75 & 53.2 & 16 & 11.4 \\
\hline Unknown & 2 & 0.6 & 0 & - & 2 & 100.0 & 0 & - \\
\hline
\end{tabular}


Table 1 Baseline characteristics of the 346 participants, by number of doses of HBV vaccine (Continued)

\begin{tabular}{|c|c|c|c|c|c|c|c|c|}
\hline \multirow[t]{2}{*}{ Variables } & \multicolumn{2}{|c|}{ Overall } & \multicolumn{2}{|c|}{ Incomplete vaccination status } & \multicolumn{2}{|c|}{ Complete vaccination status } & \multicolumn{2}{|c|}{ Unknown vaccination status } \\
\hline & $\#$ & $\mathrm{Col} \%$ & $\#$ & Row \% & $\#$ & Row \% & $\#$ & Row \% \\
\hline \multicolumn{9}{|c|}{ Smoking History } \\
\hline Absent & 28 & 8.1 & 18 & 64.3 & 5 & 17.9 & 5 & 17.9 \\
\hline Present & 318 & 91.9 & 112 & 35.2 & 176 & 55.4 & 30 & 9.4 \\
\hline Unknown & 0 & 0 & 0 & - & 0 & - & 0 & - \\
\hline \multicolumn{9}{|l|}{ Liver Disease } \\
\hline No & 282 & 81.5 & 100 & 35.5 & 155 & 55.0 & 27 & 9.6 \\
\hline Yes & 43 & 12.4 & 18 & 41.9 & 19 & 44.2 & 6 & 14.0 \\
\hline Unknown & 21 & 6.1 & 12 & 57.1 & 7 & 33.3 & 2 & 9.5 \\
\hline \multicolumn{9}{|l|}{ HCV status } \\
\hline Negative & 247 & 71.4 & 105 & 42.5 & 114 & 46.2 & 28 & 11.3 \\
\hline Positive & 95 & 27.4 & 24 & 25.3 & 65 & 68.4 & 6 & 6.3 \\
\hline Unknown & 4 & 2.7 & 1 & 25.0 & 2 & 50.0 & 1 & 25.0 \\
\hline \multicolumn{9}{|c|}{ Green Book risk factors* } \\
\hline 0 & 77 & 22.3 & 45 & 58.4 & 17 & 22.1 & 15 & 19.5 \\
\hline 1 & 89 & 25.7 & 36 & 40.5 & 46 & 51.7 & 7 & 7.9 \\
\hline 2 or more & 157 & 45.4 & 36 & 22.9 & 110 & 70.1 & 11 & 7.0 \\
\hline Unknown & 23 & 6.6 & 13 & 56.5 & 8 & 34.8 & 2 & 8.7 \\
\hline
\end{tabular}

Complete vaccination status was recorded as three or more doses. C/E Central and Eastern, Col column, IDU injecting drug use, HCV Hepatitis C virus *Green Book risk factors include current or intermittent drug use (history of IDU and current IDU), being imprisoned, having liver disease and additionally being infected with HCV on top of having liver disease

\section{Predictors of incomplete vaccine status}

In univariable and multivariable models (Table 2), 63 individuals with missing data (28 missing information on exposures, 35 missing information on the outcome of interest) were excluded and age was included as a linear variable $(p=0.34)$.

Within the univariable models, Green Book risk factors were initially examined within a single variable. Having two or more risk factors versus none was associated with protection against having an incomplete HBV vaccination status (odds ratio [OR] 0.13 [95\% confidence interval $\{\mathrm{CI}\}$ 0.07-0.26). Having one risk factor was also associated with protection, albeit to a lesser degree $(0.32$ [0.16-0.66]), although the CIs between the two strata overlapped. Being female (2.78 [1.59-4.89], $p<0.001$ ) was associated with higher odds of having an incomplete vaccination status. There was also an association between people who have smoked (either currently or in the past) with having a complete $\mathrm{HBV}$ vaccination status (5.73 [2.06-15.88], $p<0.001)$.

In a multivariable model, the association between Green Book risk factors and incomplete vaccination status was maintained (one factor 0.43 [0.20-0.92]); two or more factors, 0.19 [0.09-0.39]; overall $p$-value $<0.001)$.) Being female (2.37 (1.24-4.57), $p=0.01$ ) also remained associated with incomplete vaccination.
There was no statistical evidence for interactions between Green Book risk factors and homelessness (LRT $p=0.79$ ), Green Book risk factors and alcohol abuse $(p=0.24)$, ethnicity and birthplace $(p=0.84)$, or homelessness and alcohol abuse $(p=0.97)$.

Additional analyses were also undertaken examining the impact of the Green Book risk factors (drug use, imprisonment/arrest, history of liver disease, HCV status) as individual variables (Table 3). Intravenous drug use (history 0.17 [0.06-0.49]); current, 0.23 [0.08-0.62]; overall $p$-value 0.004 ) was associated with protection against incomplete $\mathrm{HBV}$ vaccination.

\section{Reasons for incomplete vaccination}

Specific reasons for not receiving any doses of $\mathrm{HBV}$ vaccine were declared by 85 participants (Table 4). The most common reason was never being offered vaccination, with $80 \%(68 / 85)$ of participants stating this as a reason for no vaccination. $41 \%(28 / 68)$ of participants who reported never having been offered the vaccine had at least one of the factors listed in the Green Book, identifying them as targets for the pre-exposure immunisation programme.

Twenty two of 42 participants who had an incomplete vaccination status (one or two doses) gave a reason for not completing the vaccine schedule. The most common 
Table 2 Factors associated with an incomplete HBV vaccination course (less than 3 doses) in hard-to-reach individuals

\begin{tabular}{|c|c|c|}
\hline \multirow[t]{2}{*}{ Variable } & \multirow{2}{*}{$\begin{array}{l}\text { Univariable } \\
\text { regression } \\
\text { OR }(95 \% \mathrm{Cl})\end{array}$} & \multirow{2}{*}{$\begin{array}{l}\text { Multivariable } \\
\text { regression } \\
\text { OR }(95 \% \mathrm{Cl})\end{array}$} \\
\hline & & \\
\hline Gender & $p<0.001$ & $p=0.01$ \\
\hline Male & (base) & (base) \\
\hline Female & $2.78(1.59-4.89)$ & $2.37(1.24-4.57)$ \\
\hline Age (linear) & $p=0.80$ & $p=0.07$ \\
\hline $19-29$ & (base) & (base) \\
\hline per 10 year increase & $1.03(0.82-1.30)$ & $1.30(0.98-1.72)$ \\
\hline Ethnicity & $p=0.29$ & $p=0.90$ \\
\hline White C/E European & $1.28(0.69-2.36)$ & $1.16(0.58-2.34)$ \\
\hline White Other & (base) & (base) \\
\hline Black African & $2.57(1.04-6.38)$ & $1.27(0.37-4.33)$ \\
\hline Black Other & $0.91(0.45-1.89)$ & $0.77(0.34-1.76)$ \\
\hline Mixed/Other & $1.03(0.43-2.46)$ & $0.83(0.32-2.18)$ \\
\hline Birthplace & $p=0.06$ & $p=0.65$ \\
\hline UK born & (base) & (base) \\
\hline Not UK born & $1.7(0.97-2.99)$ & $1.19(0.56-2.51)$ \\
\hline Homelessness & $p=0.02$ & $p=0.31$ \\
\hline Never & (base) & (base) \\
\hline History & $0.34(0.16-0.74)$ & $0.68(0.28-1.67)$ \\
\hline Current & $0.62(0.31-1.22)$ & $1.11(0.49-2.50)$ \\
\hline Excessive alcohol consumption & $p=0.24$ & $p=0.65$ \\
\hline No & (base) & (base) \\
\hline Yes & $0.74(0.57-1.03)$ & $0.88(0.50-1.54)$ \\
\hline Smoking history & $p<0.001$ & $p=0.02$ \\
\hline Absent & (base) & (base) \\
\hline Present & $0.17(0.06-0.46)$ & $0.29(0.09-0.89)$ \\
\hline Green Book risk factors* & $p<0.001$ & $p<0.001$ \\
\hline 0 & (base) & (base) \\
\hline 1 & $0.32(0.16-0.66)$ & $0.43(0.20-0.92)$ \\
\hline 2 or more & $0.13(0.07-0.26)$ & $0.19(0.09-0.39)$ \\
\hline
\end{tabular}

All models present a complete case analysis where only participants with no missing data were included $(n=283)$. Likelihood ratio tests were used to calculate p-values. Multivariable model adjusts for all listed variables. *Green Book risk factors include current or intermittent drug use (history of IDU and current IDU), being imprisoned, having liver disease and additionally being infected with HCV on top of having liver disease. C/E Central and Eastern, $C$ Confidence Interval, IDU injecting drug use, $H C V$ Hepatitis $C$ virus, $O R$ odds ratio

reason was that they did not return after their initial dose(s) (Table 4).

\section{Discussion}

In a population of hard-to-reach individuals from homeless and outreach centres across London, the study found that only $52 \%$ had received a full three-dose course of HBV vaccine, with $74 \%$ of participants reporting at least one dose. Critically, although the proportion of individuals
Table 3 Extended multivariable analyses, separating the Green Book risk factor exposure variable into four separate variables

\begin{tabular}{|c|c|}
\hline Variable & OR $(95 \% \mathrm{Cl})$ \\
\hline Gender & $p=0.005$ \\
\hline Male & (base) \\
\hline Female & $2.72(1.35-5.48)$ \\
\hline Age (linear) & $p=0.12$ \\
\hline $19-29$ & (base) \\
\hline per 10 year increase & $1.22(0.91-1.64)$ \\
\hline Ethnicity & $p=0.89$ \\
\hline White C/E European & $1.12(0.53-2.37)$ \\
\hline White Other & (base) \\
\hline Black African & $1.32(0.36-4.86)$ \\
\hline Black Other & $0.74(0.31-1.78)$ \\
\hline Mixed/Other & $0.82(0.30-2.28)$ \\
\hline Birthplace & $p=0.66$ \\
\hline UK born & (base) \\
\hline Not UK born & $0.83(0.38-1.81)$ \\
\hline Homelessness & $p=0.62$ \\
\hline Never & (base) \\
\hline History & $0.72(0.29-1.81)$ \\
\hline Current & $1.06(0.45-2.50)$ \\
\hline Excessive alcohol consumption & $p=0.53$ \\
\hline No & (base) \\
\hline Yes & $0.72(0.38-1.31)$ \\
\hline History of smoking & $p=0.17$ \\
\hline No & (base) \\
\hline Yes & $0.44(0.13-1.45)$ \\
\hline Drug Use & $p=0.004$ \\
\hline No drug use & (base) \\
\hline Non IDU (History or current) & $0.55(0.23-1.32)$ \\
\hline History of IDU & $0.17(0.06-0.49)$ \\
\hline Current IDU & $0.23(0.08-0.62)$ \\
\hline Imprisonment/Arrested & $p=0.03$ \\
\hline Neither & $1.79(0.68-4.69)$ \\
\hline Arrested but not imprisoned & $2.59(1.27-5.29)$ \\
\hline Imprisoned & (base) \\
\hline History of liver disease & $p=0.14$ \\
\hline No & (base) \\
\hline Yes & $1.97(0.81-4.79)$ \\
\hline HCV status & $p=0.54$ \\
\hline Negative & (base) \\
\hline Positive & $1.47(0.67-3.24)$ \\
\hline
\end{tabular}

Model presents a complete case analysis where only participants with no missing data were included $(n=283)$. Likelihood ratio tests were used to calculate $p$-values. *Green Book risk factors include current or intermittent drug use (history of IDU and current IDU), being imprisoned, having liver disease and additionally being infected with HCV on top of having liver disease. C/E - Central and Eastern; Cl confidence interval, HCV Hepatitis $C$ virus, IDU injecting drug use, $O R$ odds ratio; $\mathrm{p}=p$-value 
Table 4 Questionnaires captured reasons for participants not being vaccinated against HBV or not completing the schedule

\begin{tabular}{lll}
\hline Reason for no/incomplete vaccination & Frequency & Percentage (\%) \\
\hline No vaccination & 85 & 100 \\
Never been offered the vaccine & 68 & 80 \\
Already had Hepatitis B & 8 & 9.4 \\
Do not have enough time & 3 & 3.5 \\
Refused vaccination & 2 & 2.4 \\
Allergic to other vaccines/potentially & 1 & 1.2 \\
this vaccine & & \\
Dislike needles & 1 & 1.2 \\
Do not believe in vaccination & 1 & 1.2 \\
Worried about side-effects & 1 & 1.2 \\
Incomplete vaccination & 22 & 100 \\
Did not return & 13 & 59.1 \\
Do not have enough time & 5 & 22.7 \\
Infected with Hepatitis B virus & 2 & 9.1 \\
between doses & & 4.6 \\
Side effects/allergy to first dose(s) & 1 & 4.6 \\
Awaiting third dose & 1 & \\
\hline
\end{tabular}

with an incomplete vaccine course decreased as the number of Green Book risk factors increased, two fifths of individuals lacked full vaccine protection among individuals with one factor and nearly a quarter among individuals with two or more. The presence of only a single factor should be sufficient to trigger implementation of the Green Book guidelines. Regression analyses confirmed these findings and also highlighted the association of IDU with vaccine coverage. Additionally, we found that females were more likely to have an incomplete vaccination status. The main reasons for given for participants having an incomplete vaccination status was that they had not been offered vaccination, or they had not returned to complete the schedule.

As well as detailed documentation of vaccine coverage in this critical population group for viral elimination, this is the first study, to our knowledge, to examine the relationship between Green Book risk factors and self-declared vaccine uptake. The level of uptake documented within PWIDs in our study (31\%) falls within the range reported from previous studies in PWIDs (27-66\%), [24-26] although it is lower than the latest figures charted by PHE in PWIDs in 2016 of 71\% [27]. UK prisons have reported varying levels of HBV vaccine uptake (22-70.2\%), depending on the type and location [28-31]. There is a lack of evidence of HBV vaccine uptake in the homeless, although a recent cross-sectional survey of a London homeless population has estimated the prevalence of past HBV infection as $10.4 \%$ and identified the importance of maximising vaccination uptake in this group [9]. Similarly, our study included a number of homeless people without the presence of other risk factors, who are not targets for the pre-exposure HBV immunisation programme per se.

Interestingly, we also see $22.1 \%$ of people reporting a complete vaccination status in the presence of no Green Book risk factors, potentially reflecting previous travel history, and also the nature of the population eligible for the overarching trial i.e. individuals thought to be at higher risk of chronic hepatitis $\mathrm{C}$.

In agreement with previous studies in prisons, this study found females were less likely to have reported receiving three doses of HBV vaccine [29,32]. This could be explained by both systems-related and personal factors, including healthcare workers prioritising males, as most UK hepatitis cases (70.4\%) are reported in men [3].

Our study also documents the self-declared reasons of the participants about their lack of, or incomplete, $\mathrm{HBV}$ vaccine uptake. Critically, among the non-vaccinated, $80 \%$ declared that they had not been offered the vaccine, suggesting a lack of vaccine availability or staff knowledge of the participants and their risk factors. Similar healthcare system factors have been noted by nurses in a previous study [24].

The principle limitation is that the study relies on self-declared vaccine uptake. Due to unavailable data, sexual preferences (such as men who have sex with men and condom-less sex) could not be tested for association with HBV vaccine uptake. This study recruited a specific population that was in contact with outreach services to a trial of Peer Advocates to improve engagement with healthcare services and thus will not be representative of the entire UK hard-to-reach population. Our study undertook a complete case analysis, thus excluding data from 63 patients, of whom 35 had an unknown vaccination status. We note that the population with an unknown status may be older, with a differing history of drug use, and imprisonment/arrest, thus slightly limiting the generalisability of our findings.

Encouragingly, our analyses demonstrate that having a Green Book risk factor is associated with receipt of a full course of HBV vaccination, however, two fifths of individuals with only one Green Book risk factor reported an incomplete vaccine course and one fifth with two or more factors. More therefore needs to be done to improve coverage, particularly among groups with the risk factors that do not already lead to greater engagement with care e.g. individuals with chronic HCV or liver disease. This study has highlighted that females have an increased likelihood of incomplete vaccination, which is of particular note, given that women tend to engage better with healthcare in the general population. There was also a lack of convincing evidence of the impact $\mathrm{HCV}$ status or liver disease are associated with vaccination status. Together with our analysis, of the self-declared reasons for an incomplete vaccination status, this suggests that there is a need for strengthening awareness 
about vaccine eligibility among the relevant population groups and healthcare workers. Further qualitative research should be done to look into the barriers and enablers for returning and to help improve policy and practice. One suggestion would be incentives to help with adherence to the multi-dose vaccine schedule [33].

\section{Conclusions}

Within this study of HBV vaccination uptake among hard-to-reach population groups in London, UK, we document approximately 50\% coverage of the full vaccine course and- critically- surprisingly low coverage in the presence of the risk factors that are national indicators for vaccination. We note particular population groups associated with poorer vaccine uptake and the need for better engagement of these groups with vaccine delivery systems.

\section{Additional files}

Additional file 1: Study Questionnaire. The study questionnaire captured social and medical history, demographic factors, information about HBV vaccination status and reasons for incomplete vaccination if applicable. It was completed by individuals consenting to participate in a randomised controlled trial of a peer intervention to promote engagement with hepatitis C services. (DOCX 824 KB)

Additional file 2: Baseline characteristics of the 346 participants, with column percentages. (DOCX $30 \mathrm{~KB})$

\section{Abbreviations}

C/E: Central and Eastern; Cl: Confidence interval; HALT: Hepatitis and Latent Tuberculosis; HBsAg: Hepatitis B surface antigen; HBV: Hepatitis B virus; HCV: Hepatitis C virus; IDU: Injecting/intravenous drug use; LR: Likelihood ratio; OR: Odds Ratio; PWID: People who inject drugs; UK: United Kingdom

\section{Acknowledgements}

Not applicable.

\section{Funding}

This report is independent research funded by the National Institute for Health Research Policy Research Programme ("Effectiveness of testing for treatment of hard-to-reach groups for latent tuberculosis, hepatitis B virus and hepatitis C virus in England: The HALT Study", 015/0306). The views expressed in this publication are those of the author(s) and not necessarily those of the NHS, the National Institute for Health Research or the Department of Health and Social Care. The study funders and sponsor had no role in the design of the study; the collection, analysis, and interpretation of the data; in the writing of the paper; and in the decision to submit it for publication.

\section{Availability of data and materials}

The datasets generated and/or analysed during the current study are not publicly available due to consent for data sharing not being obtained at enrolment, but aggregate data are available from the corresponding author on reasonable request.

\section{Authors' contributions}

IA and HRS designed the study. JS, MF and JM acquired the data. JT analysed and interpreted the data and drafted the manuscript. All authors were involved in the interpretation of the data and revising the manuscript. All authors read and approved the final manuscript.

\section{Ethics approval and consent to participate}

This secondary data analysis was reviewed and approved as part of the HALT: Hepatitis trial by the National Research Ethics Service (NRES) Committee
London, Brent (ref: 13/LO/0077). It was registered as ISRCTN24707359. All participants gave written informed consent to be part of the study.

\section{Consent for publication \\ Not applicable.}

\section{Competing interests}

HRS reports funding from the Department of Health during the course of the study. JS, JM and MF report funding from the Department of Health and NIHR Clinical Research Network, UK, during the conduct of the study. GF reports personal fees from AbbVie, Gilead and Merck during the conduct of the study. All other authors report that they have no competing interests.

\section{Publisher's Note}

Springer Nature remains neutral with regard to jurisdictional claims in published maps and institutional affiliations.

\section{Author details}

${ }^{1}$ Institute for Global Health, University College London, 4th floor, Mortimer Market Centre, off Capper Street, London WC1E 6JB, UK. ${ }^{2}$ Usher Institute of Population Health Sciences and Informatics, The University of Edinburgh, 30 West Richmond Street, Edinburgh EH8 9DX, UK.

Received: 14 November 2018 Accepted: 20 March 2019

Published online: 02 May 2019

\section{References}

1. World Health Organization. Global hepatitis report 2017. World Health Organization; 2017. http://www.who.int/iris/handle/10665/255016. Accessed 10 Nov 2018.

2. World Health Organization. Prevention \& Control of viral hepatitis infection: framework for global action. World Health Organization; 2012. http://www. who.int/hiv/pub/hepatitis/Framework/en/. Accessed 10 Nov 2018.

3. Public Health England. Acute hepatitis B (England): annual report for 2017, vol. 12; 2017.

4. Ahmed F, Foster GR. Global hepatitis, migration and its impact on Western healthcare. Gut. 2010:59:1009-11.

5. Elwell-Sutton T, Fok J, Albanese F, Mathie H, Holland R. Factors associated with access to care and healthcare utilization in the homeless population of England. J Public Health Med. 2017. https:/doi.org/10.1093/pubmed/fdw008.

6. The Hepatitis C Trust. The UK commits itself to the elimination of viral hepatitis as a public health threat by 2030. 2016. http://www.hepctrust.org. uk/blog/jun-2016/uk-commits-itself-elimination-viral-hepatitis-public-healththreat-2030. Accessed 10 Nov 2018.

7. World Health Organisation. Hepatitis B Fact Sheet 2017. http://www.who. int/mediacentre/factsheets/fs204/en/. Accessed 16 Aug 2017.

8. Public Health England. Hepatitis B. In: Immunisation against infectious disease: the green book. https://assets.publishing.service.gov.uk/ government/uploads/system/uploads/attachment_data/file/628602/ Greenbook_chapter_18.pdf. Accessed 10 Nov 2018.

9. Aldridge RW, Hayward AC, Hemming S, et al. High prevalence of latent tuberculosis and bloodborne virus infection in a homeless population. Thorax. 2018;73:557-64.

10. Nyamathi AM, Sinha K, Saab S, et al. Feasibility of completing an accelerated vaccine series for homeless adults. J Viral Hepat. 2009;16:666-73.

11. Bramley G, Fitzpatrick S, Edwards J, Ford D, Johnsen S, Sosenko F, \& Watkins D. Hard Edges: mapping severe and multiple disadvantage in England. 2015. https://lankellychase.org.uk/wp-content/uploads/2015/07/Hard-EdgesMapping-SMD-2015.pdf. Accessed 3 Feb 2019.

12. Klinkenberg WD, Caslyn RJ, Morse GA, Yonker RD, McCudden S, Ketema F, Constantine NT. Prevalence of human immunodeficiency virus, hepatitis b, and hepatitis $\mathrm{c}$ among homeless persons with co-occurring severe mental illness and substance use disorders. Compr Psychiatry. 2003:44:293-302.

13. Badiaga S, Raoult D, Brouqui P. Preventing and controlling emerging and reemerging transmissible diseases in the homeless. Emerg Infect Dis. 2008 https://doi.org/10.3201/eid1409.082042

14. Tucker JS, Wenzel SL, Golinelli D, Kennedy DP, Ewing B, Wertheimer S. Understanding heterosexual condom use among homeless men. AIDS Behav. 2013. https://doi.org/10.1007/s10461-012-0165-6.

15. The Innovation and Good Practice Team. Working with prison leavers, resource for homelessness services. In: Homeless link; 2017. https://www. 
homeless.org.uk/sites/default/files/site-attachments/ Working\%20with\%20prison\%20leavers\%20March\%202018.pdf. Accessed 3 Feb 2019

16. Trebilcock J. No winners: the reality of short term prison sentences. In: The Howard league for penal reform; 2011. https://howardleague.org/wpcontent/uploads/2016/03/No-Winners.pdf. Accessed 3 Feb 2019.

17. Seymour M, Costello L. A study of the number, profile and progression routes of homeless persons before the court and in custody. 2005. https:// arrow.dit.ie/cgi/viewcontent.cgi?referer=\&httpsredir=1\&article= 1005\&context=cserrep. Accessed 3 Feb 2019

18. Shelter. Far from alone: Homelessness in Britain in 2017. 2017. http:// england.shelter.org.uk/_data/assets/pdf_file/0017/1440053/8112017_Far_ From_Alone.pdf. Accessed 3 Feb 2019.

19. Rough Sleeping in London (CHAIN Reports). Greater London Authority. London. 2017. https://data.Iondon.gov.uk/dataset/chain-reports. Accessed 3 Feb 2019.

20. Hewett N, Halligan A. Homelessness is a healthcare issue. J R Soc Med. 2010. https://doi.org/10.1258/jrsm.2010.10k028.

21. Jit M, Stagg HR, Aldridge RW, White PJ, Abubakar I. Dedicated outreach service for hard to reach patients with tuberculosis in London: observational study and economic evaluation. BMJ. 2011. https://doi.org/10.1136/bmj.d5376.

22. Stagg HR, Surey J, Francis M, MacLellan J, Foster GR, Charlett A, Abubakar I. Improving engagement with healthcare in hepatitis $\mathrm{C}$ : a randomised controlled trial of a peer support intervention. BMC Med. 2019. https://doi. org/10.1186/s12916-019-1300-2

23. ISRCTN registry. The HALT hepatitis study. 2012. http://www.isrctn.com/ ISRCTN24707359. Accessed 10 Nov 2018.

24. McGregor J, Marks PJ, Hayward A, Bell Y, Slack RCB. Factors influencing hepatitis $B$ vaccine uptake in injecting drug users. J Public Health Med. 2003;25:165-70

25. Lamagni TL, Davison KL, Hope VD, Luutu JW, Newham JA, Parry JV, Gill ON. Poor hepatitis B vaccine coverage in injecting drug users: England, 1995 and 1996. Commun Dis Public Health. 1999;2:174-7.

26. Budd J, Robertson R, Elton R. Hepatitis B vaccination and injecting drug users. Br J Gen Pract. 2004:54:444-7.

27. Public Health England. Shooting up: infections among people who injected drugs in the UK, update November 2016. In: Public Health England; 2017. https://assets.publishing.service.gov.uk/government/uploads/system/ uploads/attachment_data/file/567231/Shooting_Up_2016_Update.pdf. Accessed 10 Nov 2018.

28. Beck CR, Cloke R, O'Moore É, Puleston R. Hepatitis B vaccination coverage and uptake in prisons across England and Wales 2003-2010: a retrospective ecological study. Vaccine. 2012;30:1965-71.

29. Gilbert RL, Costella A, Piper M, Gill ON. Increasing hepatitis B vaccine coverage in prisons in England and Wales. Commun Dis Public Health. 2004;7:306-11.

30. Mahto M, Zia S. Measuring the gap: from Home Office to the National Health Service in the provision of a one-stop shop sexual health service in a female prison in the UK. Int J of STD AIDS. 2008;19:586-9.

31. Plugge EH, Yudkin PL, Douglas N. Predictors of hepatitis B vaccination in women prisoners in two prisons in England. J Public Health Med. 2007;29:429-33.

32. Hutchinson SJ, Wadd S, Taylor A, Bird SM, Mitchell A, Morrison DS, et al. Sudden rise in uptake of hepatitis $B$ vaccination among injecting drug users associated with a universal vaccine programme in prisons. Vaccine. 2004;23: 210-4.

33. Weaver T, Metrebian N, Hellier J, Pilling S, Charles V, Little N, et al. Use of contingency management incentives to improve completion of hepatitis $B$ vaccination in people undergoing treatment for heroin dependence: a cluster randomised trial. Lancet. 2014. https://doi.org/10.1016/S01406736(14)60196-3.

Ready to submit your research? Choose BMC and benefit from:

- fast, convenient online submission

- thorough peer review by experienced researchers in your field

- rapid publication on acceptance

- support for research data, including large and complex data types

- gold Open Access which fosters wider collaboration and increased citations

- maximum visibility for your research: over $100 \mathrm{M}$ website views per year

At BMC, research is always in progress.

Learn more biomedcentral.com/submissions 